\title{
Organik ve organomineral gübrelerin Prima üzüm çeşidinde verim, kalite ve bitki besleme üzerine etkileri
}

\section{Effects of organic and organomineral fertilizers on yield, quality and plant nutrition in Prima grape variety}

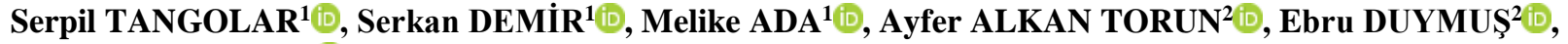 Semih TANGOLAR ${ }^{1}$ (D)}

${ }^{1}$ Çukurova Üniversitesi, Ziraat Fakültesi, Bahçe Bitkileri Bölümü, Sarıçam, Adana

${ }^{2}$ Çukurova Üniversitesi, Ziraat Fakültesi, Toprak Bilimi ve Bitki Besleme Bölümü, Sarıçam, Adana

Sorumlu yazar (Corresponding author): S. Tangolar, e-posta (e-mail): stangolar@cu.edu.tr

Yazar(lar)e-posta (Authore-mail): temirsrkn@gmail.com, melikeada46@gmail.com, atorun@cu.edu.tr, ebruduymus@yahoo.com, tangolar@cu.edu.tr

\section{MAKALE BİLGISİ}

Alınış tarihi 10 Ağustos 2020

Düzeltilme tarihi 22 Ekim 2020

Kabul tarihi 22 Ekim 2020

\section{Anahtar Kelimeler:}

Bağcllk

Asma

Gübreleme

Klorofil

Ekolojik bağcılık

\begin{abstract}
ÖZ
Organik ve organomineral sıvı gübrelerin, alternatif bitki besleme ürünleri olarak bahçe bitkilerinde kullanımı zamanla yaygınlaşmaktadır. Bu nedenle gübrelerin bağcılık bölgeleri için önemli yeni bazı üzüm çeşitlerinde etkilerinin denenmesinin faydalı olacağ düşünülmüștür. $\mathrm{Bu}$ araştırma, Prima üzüm çeşidinde yürütülmüștür. Çalışmada, yapraktan ve

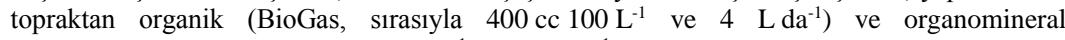
(AminoSEL-K, sırasıyla 300 cc $100 \mathrm{~L}^{-1}$ ve $4 \mathrm{~L} \mathrm{da}^{-1}$ ), gübre uygulamalarının tek başına ve birlikte uygulanmasının etkilerine bakılmıştır. Araştırma sonucunda en yüksek verim, salkım ağırlığı, büyüklüğü ve suda çözünebilir kuru madde değerlerinin (sırasıyla $9251 \mathrm{~g} \mathrm{omca}^{-1}$, $462.6 \mathrm{~g}$ ve \%15.58) organomineral uygulamasında olduğu belirlenmiștir. Organik+organomineral uygulaması tane büyüklüğünü ayrı ayrı ve birlikte uygulandığında kontrol uygulamasına göre artırmıștır. Topraktan uygulamanın salkım ve tane büyüklüğünü artırdığı saptanmıştır. Topraktan ve yapraktan uygulama şekli toprak ve yaprağın besin maddesi kapsamında önemli farklılık oluşturmamıştır. Organik+organomineral gübre uygulamasında toprakta potasyum; yalnız organik uygulamasında toprakta magnezyum, demir, çinko ve bakır konsantrasyonları yüksek bulunmuştur. Sonuçta, Prima çeşidinde farklı gübre ve uygulama şekli uygulamalarının incelenen özelliklere göre farklı etkide bulunduğu saptanmıştır. Ancak, bu gübrelerin etkisi konusunda kesin yargıya varılabilmesi için çalışmanın izleyen yıllarda da sürdürülmesinin uygun olacağı kanısına varılmıştır.
\end{abstract}

\section{ARTICLE INFO}

Received 10 August 2020

Received in revised form 22 October 2020

Accepted 22 October 2020

\section{Keywords:}

Viticulture

Grapevine

Fertilization

Chlorophyll

Ecological viticulture

\begin{abstract}
Use of organic and organomineral liquid fertilizers as alternative plant nutrition products is being more common in horticultural crops. For this reason it is thought that it can be good to use these fertilizers at some of the important grape varieties for the viticultural regions. This research was conducted in Prima grape variety. In the study, the effects of separate and combined applications of organic (BioGas, $400 \mathrm{cc} 100 \mathrm{~L}^{-1}$ and $4 \mathrm{~L} \mathrm{da}^{-1}$, respectively) and organomineral (AminoSEL-K, $300 \mathrm{cc} 100 \mathrm{~L}^{-1}$ and $4 \mathrm{~L} \mathrm{da}^{-1}$, respectively) liquid fertilizers from leaves and soil were compared. To determine the effect of fertilizer applications, grape yield and quality, and plant nutrition characteristics were examined. The highest yield, cluster weight and total soluble solids values ( $9251 \mathrm{~g}$ vine $\mathrm{e}^{-1}, 462.6 \mathrm{~g}$ and $15.58 \%$, respectively) were recorded in organomineral application. Organic+organomineral applications when applied separately and together increased berry size compared to control application. It is seen that organic and organomineral fertilizer application from soil increased cluster and berry size. Effect of application method (to soil and to leaf) on mineral concentrations of soil and leaf was not significant. Organic+organomineral fertilizer for Potassium in soil; organic fertilizer application for magnesium, iron, zinc and copper in soil was found to be higher. As a result, it is determined that at Prima variety different fertilizer and different application methods showed different effects. However, it would be appropriate to continue the study in the following years in order to reach more definite conclusion on the effect of these fertilizers.
\end{abstract}




\section{Giriş}

Sentetik mineral gübreleme ile toprağa ve suya karışan zararlı maddeleri bünyesinde biriktiren bitkilerin tüketilmesi insanlarda ve diğer canlılarda önemli sağlık ve çevre sorunlarına yol açmaktadır (Akural 2009). Sentetik kimyasal gübrelerin aşırı kullanımının insan, çevre ve toprakta yol açtığı tahribatları engellemek amaciyla organik veya organomineral gübre kullanımı, sürdürülebilir tarımın bileşenlerinden biri olarak değerlendirilebilmektedir. Organik gübreler, makro ve mikro element içeriklerinin değişken olmasından kaynaklı farklılık göstermektedir (Katkat 2018). Organomineral gübreler ise organik gübrelerde eksik görülen mineral maddelerin ilave edilmesiyle oluşturulmaktadır. Bu konuda yapılan yayınlardaki tartışmalarda ve elde edilen sonuçlarda bitki besin elementi ilavesi ve toprak kalitesinin artırılması bakımından kimyasal gübrelere en iyi alternatifin organomineral gübreler olduğu ifade edilmektedir (Kominko ve ark. 2016).

Ülkemizde organomineral gübrelerin kullanıldığ araştırmalarda, araştırmacıların organomineral gübre kaynağ olarak; ticari gübre, organik gübre ve mineral gübre karışımı yoluyla kendi formüle ettikleri organomineral gübreleri kullandıkları belirlenmiştir (Katkat 2018). Bağlarda organik gübrelerin kullanıldığı çok sayıda araştırma bulunmasına karşın (Tangolar ve ark. 2007; Morlat 2008; Özdemir 2018; Özdemir ve ark. 2018; Tangolar ve ark. 2019, Kolbe ve ark. 2019) alternatif bir gübre kaynağı olarak organomineral gübrelerin kullanıldığı sınırlı sayıda çalışma bulunmaktadır.

Organomineral gübrelerin kullanıldığı çalışmalar incelendiğinde; bezelye (Ateş ve Tekeli 2017), 1sırgan (Çalışkan ve Ayan 2011), kavun (Fernandes ve ark. 2003), karpuz (Ojo ve ark. 2014), kabak (Olaniyi ve Akanbi 2007), hiyar (Olaniyi ve ark. 2009), lahana (Olaniyi ve Ojetayo 2011), marul (Dannehl ve ark. 2016), bamya (Olaniyi ve ark. 2010), antepfistığı (Aslan 2018), zeytin (Pekcan ve ark. 2009), kivi (Tarakçıŏlu ve Aşkın 2006), asma (Özdemir 2018; Özdemir ve ark. 2018) gibi birçok bitki türünde denendikleri ve olumlu sonuçların alındığ 1 saptanmıştır.

Organomineral gübre kullanımının kivi bitkisinde meyve tutumunu arttırmakla birlikte, meyve büyüklüğünde azalmaya yol açtığı belirlenmiştir (Tarakçıoğlu ve Aşkın 2006). Zeytinde yapılan bir çalışmada mineral gübre ve çiftlik gübresinin beraber kullanılmasının verimi yalnızca mineral gübre kullanılmasına kıyasla arttırdı ̆̆ 2009). Aslan (2018), organomineral gübre kullanılması halinde Antepfıstığında ağaç başına ortalama \%40'a varan verim artış1 elde edilebileceğini belirtmiştir. Ülkemizde organomineral gübre etkisinin asmalarda denendiği sınırlı örnekler arasında yer alan Özdemir (2018)'in araştırmasında Öküzgözü ve Boğazkere üzüm çeşitlerinin sürgün gelişimi üzerine farklı organomineral gübrelerin etkileri incelemiş; Özdemir ve ark. (2018)'nda ise Öküzgözü üzüm çeşidinin toplam fenolik, flavonoid, antosiyanin ve antiradikal aktiviteleri üzerine çalışılmış ve katı organomineral gübrelerin etkilerinin olumlu olduğu belirtilmiştir. Bunlar dışında özellikle asma verim ve kalite özellikleri üzerine sıvı organomineral gübre etkisinin incelendiği bir çalışma bilgimiz dâhilinde bulunmamaktadır.

$\mathrm{Bu}$ çalışma, organik ve organomineral sıvı gübrelerin topraktan ve yapraktan uygulanmasının asma verim, kalite ve bitki besleme üzerine olan etkileri konusundaki bilgi eksikliğine katkı sağlama amacıyla yürütülmüştür.

\section{Materyal ve Yöntem}

Araştırma, 2019 yılında Çukurova Üniversitesi Ziraat Fakültesi Bahçe Bitkileri Bölümü Araştırma ve Uygulama Bağında yürütülmüş̧ür. Bitkisel materyal olarak dikim sıklığı $3.5 \times 2 \mathrm{~m}$ olan, çift kollu kordon şeklinde terbiye edilmiş kendi kökü üzerinde yetişen Prima çeşidinin, kısa budama uygulanan 4 yaşlı asmaları kullanılmıştır.

Çalışmada yapraktan ve topraktan olmak üzere organik (BioGas, sirasiyla $400 \mathrm{cc} 100 \mathrm{~L}^{-1}$ ve $4 \mathrm{~L} \mathrm{da}^{-1}$ ) ve organomineral (AminoSEL-K, sirasiyla 300 cc $100 \mathrm{~L}^{-1}$ ve $4 \mathrm{~L} \mathrm{da}^{-1}$ ), gübre uygulamalarının ayrı ayrı ve birlikte uygulanmasının etkileri incelenmiştir. Kullanılan organik ve organomineral gübre dozları üretici firma önerisi dikkate alınarak belirlenmiştir. Yapraktan kontrol uygulaması için yalnızca su püskürtülmüş ve topraktan kontrol uygulaması için ise asmalara yalnızca su verilmiştir. Gübreler, bitkilere sürgünler $25-30 \mathrm{~cm}$ uzunluğuna geldiğinde, tane tutumunda (saçma iriliği) ve iri koruk (nohut büyüklügü̈nde) olmak üzere üç farklı dönemde uygulanmıştır.

Uygulamaların etkisini belirlemek üzere derim zamanında verim, salkım ağırlığı, salkım uzunluğu, genişliği ve büyüklüğü ile yüz tane ağırlığı, yüz tane hacmi, tane uzunluğu, genişliği ve büyüklüğü, suda çözünebilir kuru madde (SÇKM), asitlik, pH ve olgunluk indisi özellikleri incelenmiştir.

Bitkilerin tam çiçeklenme, ben düşme ve olgunluk zamanlarında sürgünün 1/3'lük orta kısmındaki yapraklarda klorofil miktarı SPAD Metre (SPAD-502 Plus); yaprak sıcaklığ $\left({ }^{\circ} \mathrm{C}\right)$ ise bir infrared termometre (ScanTemp 485) ile öğle saatlerinde ölçülmüştür.

Uygulamaların toprak ve bitki besin kapsamı üzerine etkilerinin belirlenmesi amaciyla, toprak örnekleri, gübre uygulamaları öncesinde ve derim zamanında olmak üzere iki dönemde 0-30 cm derinlikten; yaprak örnekleri ise ben düşme döneminde salkımların karşısından alınmıştır.

Toprak örneklerinde, toprak reaksiyonu $(\mathrm{pH})$ ve organik madde Jackson (1958)'a, elektriksel iletkenlik Richards (1954)'a, kireç Hızalan ve Ünal (1966)'a alınabilir formdaki fosfor Olsen ve ark. (1954)'na, potasyum, kalsiyum, magnezyum Pratt (1965)'a, demir, çinko, mangan ve bakır ise Lindsay ve Norwell (1978)'e göre belirlenmiştir.

Yaprak örnekleri yıkama, kurutma ve öğütme işlemlerinden sonra kuru yakma yöntemi ile analize hazırlanmıştır. Örneklerde toplam azot Kjeldahl yöntemine göre (Bremner 1965), toplam fosfor Vanadomolibdik sarı renk yöntemi ile spektrofotometrik olarak belirlenmiştir. Toplam potasyum, kalsiyum, magnezyum, demir, çinko, mangan ve bakır konsantrasyonları atomik absorbsiyon spektroskopisin (AAS)'de saptanmıştır (Kacar 1972).

Deneme alanının Çizelge 1'de verilen iklim verilerinden deneme süresi içinde en düşük sıcaklığın $-0.2^{\circ} \mathrm{C}$ ile Ocak ayında; en yüksek sıcaklıkların mayıs, haziran, temmuz ve ağustos aylarında (sırasıyla $39.0^{\circ} \mathrm{C}, 38.3^{\circ} \mathrm{C}, 39.0^{\circ} \mathrm{C}$ ve $39.6^{\circ} \mathrm{C}$ ) kaydedildiği; ortalama sıcaklığın $20.8^{\circ} \mathrm{C}$; toplam yağış miktarının $560 \mathrm{~mm}$; ortalama nispi nemin ise \%68.9 olarak kaydedildiği belirlenmiştir.

Deneme alanından gübre uygulaması öncesi alınan toprak örneklerinin analizleri sonunda elde edilen değerlerden toprağın $\mathrm{K}, \mathrm{Ca}, \mathrm{Mg}, \mathrm{Fe}, \mathrm{Zn}, \mathrm{Mn}$ ve $\mathrm{Cu}$ düzeyinin yeterli; P'un az olduğu belirlenmiştir. Toprağın az tuzlu, organik madde içeriğinin düşük ve hafif alkali olduğu değerlendirilmiştir (Follet 1969; Lindsay ve Norwell 1969; Wolf 1971; Tüzüner 1990) (Çizelge 2). 
Çizelge 1. Deneme alanı 2019 yılı iklim verileri (Meteoroloji 6. Bölge Müdürlüğü İncirlik Meydan Müdürlüğü). Table 1. 2019 climate data of experimental area (6. Meteorology Regional Directorate/ Incirlik Directorate).

\begin{tabular}{|c|c|c|c|c|c|c|c|c|c|c|c|}
\hline \multirow{2}{*}{ İklim Özellikleri } & \multicolumn{10}{|c|}{ Aylar } & \multirow{2}{*}{ Ortalama } \\
\hline & 1 & 2 & 3 & 4 & 5 & 6 & 7 & 8 & 9 & 10 & \\
\hline Maksimum Sicaklık $\left({ }^{\circ} \mathrm{C}\right)$ & 18.2 & 20.4 & 25.2 & 31.2 & 39.0 & 38.3 & 39.0 & 39.6 & 36.4 & 33.4 & 32.1 \\
\hline Minimum Sıcaklık $\left({ }^{\circ} \mathrm{C}\right)$ & -0.2 & 3.4 & 5.0 & 5.2 & 9.0 & 16.4 & 17.4 & 21.0 & 12.8 & 17.6 & 10.8 \\
\hline Ortalama Sicaklık $\left({ }^{\circ} \mathrm{C}\right)$ & 9.3 & 11.3 & 13.3 & 16.2 & 23.2 & 26.6 & 28.0 & 28.9 & 26.5 & 24.8 & 20.8 \\
\hline Toplam Yağıș (mm)* & 249.0 & 88.6 & 96.5 & 71.1 & 2.6 & 21.3 & 30.9 & - & - & - & 560.0 \\
\hline Nispi Nem (\%) & 70.7 & 73.6 & 72.0 & 70.9 & 60.7 & 70.6 & 69.4 & 69.1 & 62.2 & 70.1 & 68.9 \\
\hline Rüzgar hızı (m s s') & 3.9 & 3.3 & 2.9 & 2.6 & 2.7 & 2.7 & 2.8 & 2.8 & 2.9 & 3.2 & 3.0 \\
\hline
\end{tabular}

*Toplam yağış (mm) değerleri Meteoroloji Genel Müdürlüğü Yüreğir iklim istasyonundan alınmıştır.

Çizelge 2. Deneme alanı toprağının özellikleri.

Table 2. Soil characteristics of the experimental area.

\begin{tabular}{|c|c|}
\hline Makro elementler & $\left(\mathrm{mg} \mathrm{kg}^{-1}\right)$ \\
\hline $\mathrm{P}$ & 7.21 \\
\hline K & 248.0 \\
\hline $\mathrm{Ca}$ & 2004 \\
\hline $\mathrm{Mg}$ & 193.1 \\
\hline Mikro elementler & $\left(\mathrm{mg} \mathrm{kg}^{-1}\right)$ \\
\hline $\mathrm{Fe}$ & 4.59 \\
\hline $\mathrm{Zn}$ & 1.48 \\
\hline $\mathrm{Mn}$ & 17.43 \\
\hline $\mathrm{Cu}$ & 7.37 \\
\hline \multicolumn{2}{|c|}{ Diğer Toprak Parametreleri } \\
\hline $\mathrm{pH}$ & 7.6 \\
\hline $\mathrm{EC}\left(\mu \mathrm{S} \mathrm{cm} \mathrm{cm}^{-1}\right)$ & 251 \\
\hline Organik Madde (\%) & 0.74 \\
\hline Toplam Kireç (\%) & 43.80 \\
\hline
\end{tabular}

Deneme faktöriyel düzende tesadüf blokları deneme desenine göre, iki faktörlü, 3 tekerrürlü ve her tekerrürde 3 omca olacak şekilde kurulmuştur. Denemeden elde edilen verilere JMP istatistik programı kullanılarak varyans analizi uygulanmış ve farklı grupların saptanmasında \%5 önem seviyesinde LSD testinden yararlanılmıştır.

\section{Bulgular ve Tartış̧a}

Organik ve organomineral gübrelerin verim ve salkım özellikleri üzerine etkisi farklı bulunmuştur (Çizelge 3). Derim sonrası yapılan tartım ve ölçümlerde en yüksek verim (9251 $\left.\mathrm{g} \mathrm{omca}^{-1}\right)$, salkım ağırlığı (462.6 g), genişliği $(14.47 \mathrm{~cm})$ ve büyüklüğü $\left(303.7 \mathrm{~cm}^{2}\right)$ organomineral; en uzun salkım değerleri $(21.68 \mathrm{~cm})$ ise kontrol uygulamasında saptanmıştır. $\mathrm{Bu}$ salkımlar Çelik (2011)'e göre orta büyüklükte salkım grubuna (251-500 g) girmiştir. Ahmed ve ark. (2018) hurmaya tek başına organik gübre veya organik gübre ile mineral NPK kombinasyonunu (organomineral) uyguladıkları çalışmalarında, organomineral gübrenin, tek başına uygulanan organik gübreden daha yüksek verim ve meyve ağırlığı verdiğini belirlemiştir. Rozpara ve ark. (2015) ise çalışmalarında biyogübre'nin vişne ağaçlarının büyümesi ve meyvesi üzerinde olumlu etkide bulunduğunu göstermişlerdir.

Çalışmamızda organik, organomineral ve bunların kombinasyonunu oluşturan uygulamalarda dekara verimin sırasıyla, 1185, 1322, $1162 \mathrm{~kg}$ olduğu belirlenmiştir. Türkiye'de yapılan geleneksel bağcılıkta dekara üzüm verimi istatistiklerde (TÜIK 2018) $865 \mathrm{~kg} \mathrm{da}^{-1}$ olarak verilmektedir. Buradan da anlaşılabileceği gibi çalışmamızda uygulamalardan elde edilen dekara verim Türkiye ortalamasının üzerindedir. Tangolar ve ark. (2019) bağ toprağına uyguladıkları farklı organik materyallerin verim üzerine etkisini inceledikleri çalışmalarında en yüksek verimi saman+çiflik gübresi uygulamasında dekara $2984 \mathrm{~kg} \mathrm{da}^{-1}$ olarak belirlemişlerdir. Farklılığın söz konusu çalışmada sık dikimin yapılmasından ve asmaların daha yaşlı olmasından kaynaklandığı değerlendirilmiştir. Pekcan ve ark. (2009)'nın çalışmasında zeytinde uygulanan organomineral gübrenin verim artışına neden olduğu belirlenmiştir.

Farklı gübre uygulamalarının tane ağırlığı ve hacmi ile tane genişliği üzerine etkisinin istatistiksel olarak önemli olmadığı, tane uzunluğu ve tane büyüklügü üzerine etkisinin ise önemli olduğu bulunmuştur. En yüksek tane uzunluğu ve büyüklüğü değerleri organik+organomineral uygulamasında; en düşük değerler ise kontrol uygulamasında belirlenmiştir. Tane ağırlığı, hacmi ve genişliğinde uygulama şeklinin etkisi önemli bulunmaz iken tane uzunluğu ve büyüklüğünde en yüksek değerleri (sırasıyla $18.91 \mathrm{~mm}$ ve $340.8 \mathrm{~mm}^{2}$ ) topraktan yapılan uygulamaların verdiği saptanmıştır (Çizelge 4).

Organik ve organomineral gübre uygulamalarının SÇKM ve $\mathrm{pH}$ üzerine etkisi önemli; asitlik ve olgunluk indisi üzerine etkisi istatistiksel olarak önemsiz olduğu belirlenmiştir. En yüksek SÇKM (\%15.58) ve pH (3.41) değeri organomineral uygulamasından alınmıştır. Uygulama şeklinin şıra özellikleri üzerine etkisi önemli çıkmamıştır (Çizelge 5). Tangolar ve ark. (2007)'nda da Çiloreş üzüm çeşidine uygulanan organik gübrelerin SÇKM ve asitlik üzerine etkisi önemli çıkmıştır.

Farklı gübre uygulamalarının klorofil miktarı üzerine etkisi ben düşme ve olgunluk dönemleri itibariyle önemli bulunmazken; tam çiçeklenme döneminde yapılan ölçümlerde organik+organomineral uygulamasında en yüksek klorofil değerinin (31.9) alındığı görülmüştür. Uygulama şeklinin klorofil miktarı üzerine etkisi önemli bulunmamıştır (Çizelge 6). Sarı (2019) tam ve kısıntılı sulama (\%60 seviye) ile birlikte Zn uygulaması yaptığı Alphonse Lavallee ve Italia üzüm çeşitlerinde klorofil miktarında uygulamalara göre önemli farkl11ık bulmuştur. Küçükbasmacı (2019) da dokuz farklı asma anacı üzerine aşılı Prima üzüm çeşidine iki farklı sulama uygulaması yaptığı çalışmasında uygulamaların klorofil miktarı üzerine etkisinin ölçüm zamanlarına göre değiştiğini belirlemiştir.

Organik ve organomineral gübre uygulamalarının yaprak sıcaklığı üzerine etkisi olgunluk döneminde önemli çıkmazken; tam çiçeklenme ve ben düşme dönemlerinde önemli bulunmuştur. Her iki dönemde de en yüksek değeri organomineral uygulamasının verdiği belirlenmiştir. Yaprak sıcaklığı üzerine uygulama şekli etkisinin önemli olmadığ saptanmıştır (Çizelge 7). Küçükbasmacı (2019) farklı sulama seviyeleri ile sulanan Prima üzüm çeşidinde uygulamaların taç yüzey sıcaklığı üzerine belirgin etkisinin olmadığını belirlemiştir. 
Çizelge 3. Organik ve organomineral gübre uygulamaların üzüm verimi ve salkım özellikleri üzerine etkisi.

Table 3. The effect of organic and organomineral fertilizer applications on grape yield and cluster properties.

\begin{tabular}{|c|c|c|c|c|c|}
\hline Uygulama & $\begin{array}{c}\text { Verim } \\
\left(\mathrm{g} \mathrm{omca}^{-1}\right)\end{array}$ & $\begin{array}{c}\text { Salkım } \\
\text { Ağırlığı (g) }\end{array}$ & $\begin{array}{c}\begin{array}{c}\text { Salkım Uzunluğu } \\
(\mathrm{cm})\end{array} \\
\end{array}$ & $\begin{array}{c}\text { Salkım Genişliği } \\
(\mathrm{cm})\end{array}$ & $\begin{array}{c}\begin{array}{c}\text { Salkım Büyüklüğü } \\
\left(\mathrm{cm}^{2}\right)\end{array} \\
\end{array}$ \\
\hline \multicolumn{6}{|l|}{ Gübre Tipi } \\
\hline Kontrol & $7811 b^{*}$ & $390.5 \mathrm{~b}$ & $21.68 \mathrm{a}$ & $13.40 \mathrm{~b}$ & $291.4 \mathrm{ab}$ \\
\hline Organik & 8291 b & $414.5 \mathrm{~b}$ & $20.84 \mathrm{ab}$ & $13.17 \mathrm{~b}$ & $273.9 \mathrm{~b}$ \\
\hline Organomineral & $9251 \mathrm{a}$ & $462.6 \mathrm{a}$ & $21.00 \mathrm{ab}$ & $14.47 \mathrm{a}$ & $303.7 \mathrm{a}$ \\
\hline Organik+Organomineral & $8126 b$ & $406.3 \mathrm{~b}$ & $20.10 \mathrm{~b}$ & $13.53 \mathrm{~b}$ & $272.6 \mathrm{~b}$ \\
\hline$L S D \% 5$ & 861 & 43.1 & 1.27 & 0.82 & 28.1 \\
\hline $\mathbf{P}$ & 0.0171 & 0.0171 & 0.1119 & 0.0221 & 0.0943 \\
\hline \multicolumn{6}{|l|}{ Uygulama Şekli } \\
\hline Yapraktan & 8069 & 403.5 & 20.88 & $13.06 \mathrm{~b}$ & $273.2 \mathrm{~b}$ \\
\hline Topraktan & 8671 & 433.5 & 20.93 & $14.22 \mathrm{a}$ & $297.7 \mathrm{a}$ \\
\hline$L S D \% 5$ & Ö.D. & Ö.D. & Ö.D. & 0.58 & 19.9 \\
\hline $\mathbf{P}$ & 0.0528 & 0.0528 & 0.9034 & 0.0008 & 0.0193 \\
\hline \multicolumn{6}{|l|}{ İnteraksiyon } \\
\hline$L S D \% 5$ & Ö.D. & Ö.D. & Ö.D. & Ö.D. & Ö.D. \\
\hline $\mathbf{P}$ & 0.6118 & 0.6118 & 0.1034 & 0.5766 & 0.1718 \\
\hline
\end{tabular}

Çizelge 4. Organik ve organomineral gübre uygulamalarının tane özellikleri üzerine etkisi.

Table 4. The effect of organic and organomineral fertilizer applications on berry properties.

\begin{tabular}{|c|c|c|c|c|c|}
\hline Uygulama & $\begin{array}{l}\text { Yüz Tane Ağırlığı } \\
\text { (g) }\end{array}$ & $\begin{array}{c}\text { Yüz Tane Hacmi } \\
(\mathrm{mL})\end{array}$ & $\begin{array}{c}\text { Tane Uzunluğu } \\
(\mathrm{mm})\end{array}$ & $\begin{array}{c}\text { Tane Genişliği } \\
(\mathrm{mm})\end{array}$ & $\begin{array}{c}\text { Tane Büyüklü̈̆g̈ü } \\
\left(\mathbf{m m}^{2}\right)\end{array}$ \\
\hline \multicolumn{6}{|l|}{ Gübre Tipi } \\
\hline Kontrol & 364.1 & 344 & $18.39 \mathrm{~b}^{*}$ & 17.63 & $324.5 \mathrm{~b}$ \\
\hline Organik & 373.2 & 353 & $18.39 \mathrm{~b}$ & 17.86 & $328.8 \mathrm{ab}$ \\
\hline Organomineral & 403.4 & 377 & $18.82 \mathrm{ab}$ & 17.88 & $336.7 \mathrm{ab}$ \\
\hline Organik+Organomineral & 381.6 & 361 & $19.02 \mathrm{a}$ & 18.04 & $343.5 \mathrm{a}$ \\
\hline$L S D \% 5$ & Ö.D. & Ö.D. & 0.51 & Ö.D. & 17.5 \\
\hline $\mathbf{P}$ & 0.2604 & 0.3666 & 0.0455 & 0.4096 & 0.1413 \\
\hline \multicolumn{6}{|l|}{ Uygulama Şekli } \\
\hline Yapraktan & 381.0 & 358 & $18.40 \mathrm{~b}$ & 17.70 & $325.9 \mathrm{~b}$ \\
\hline Topraktan & 380.1 & 359 & $18.91 \mathrm{a}$ & 18.00 & $340.8 \mathrm{a}$ \\
\hline$L S D \% 5$ & Ö.D. & Ö.D. & 0.36 & Ö.D. & 12.3 \\
\hline $\mathbf{P}$ & 0.9442 & 0.9508 & 0.0095 & 0.0936 & 0.0212 \\
\hline \multicolumn{6}{|l|}{ İnteraksiyon } \\
\hline$L S D \% 5$ & Ö.D. & Ö.D. & 0.72 & 0.72 & 24.7 \\
\hline $\mathbf{P}$ & 0.2196 & 0.2026 & 0.0029 & 0.002 & 0.004 \\
\hline
\end{tabular}

*: Aynı sütun içerisinde farklı harflerle gösterilen ortalamalar arasında istatistiki farklılık bulunmaktadır. P $\leq 0.05$. Ö.D.: Önemli Değil.

Çizelge 5. Organik ve organomineral gübre uygulamaların şıra özellikleri üzerine etkisi.

Table 5. The effect of organic and organomineral fertilizer applications on must properties.

\begin{tabular}{|c|c|c|c|c|}
\hline Uygulama & SÇKM (\%) & Asitlik (\%) & pH & Olgunluk İndisi \\
\hline \multicolumn{5}{|l|}{ Gübre Tipi } \\
\hline Kontrol & $15.10 \mathrm{ab}^{*}$ & 0.528 & $3.38 \mathrm{ab}$ & 28.93 \\
\hline Organik & $15.08 \mathrm{ab}$ & 0.551 & $3.36 \mathrm{ab}$ & 27.61 \\
\hline Organomineral & $15.58 \mathrm{a}$ & 0.536 & $3.41 \mathrm{a}$ & 29.43 \\
\hline Organik+Organomineral & $14.57 \mathrm{~b}$ & 0.537 & $3.33 \mathrm{~b}$ & 27.24 \\
\hline$L S D \% 5$ & 0.82 & Ö.D. & 0.06 & Ö.D. \\
\hline $\mathrm{P}$ & 0.1172 & 0.7628 & 0.1188 & 0.4150 \\
\hline \multicolumn{5}{|l|}{ Uygulama Şekli } \\
\hline Yapraktan & 15.33 & 0.533 & 3.38 & 28.96 \\
\hline Topraktan & 14.84 & 0.543 & 3.36 & 27.64 \\
\hline$L S D \% 5$ & Ö.D. & Ö.D. & Ö.D. & Ö.D. \\
\hline $\mathrm{P}$ & 0.0865 & 0.4982 & 0.2456 & 0.2224 \\
\hline \multicolumn{5}{|l|}{ İnteraksiyon } \\
\hline$L S D \% 5$ & Ö.D. & 0.064 & Ö.D. & 4.44 \\
\hline $\mathrm{P}$ & 0.1572 & 0.0045 & 0.2125 & 0.0155 \\
\hline
\end{tabular}


Çizelge 6. Organik ve organomineral gübre uygulamalarının SPAD ölçümleri üzerine etkisi.

Table 6. The effect of organic and organomineral fertilizer applications on SPAD readings.

\begin{tabular}{|c|c|c|c|}
\hline Uygulama & Tam Çiçek 14.05.2019 & Ben Düşme 24.06.2019 & Olgunluk 08.07.2019 \\
\hline \multicolumn{4}{|l|}{ Gübre Tipi } \\
\hline Kontrol & $30.5 a b^{*}$ & 39.2 & 39.9 \\
\hline Organik & $30.6 \mathrm{ab}$ & 38.2 & 40.4 \\
\hline Organomineral & $29.3 \mathrm{~b}$ & 37.4 & 39.7 \\
\hline Organik+Organomineral & $31.9 \mathrm{a}$ & 38.6 & 41.1 \\
\hline$L S D \% 5$ & 2.3 & Ö.D. & Ö.D. \\
\hline $\mathrm{P}$ & 0.0570 & 0.4655 & 0.7769 \\
\hline \multicolumn{4}{|l|}{ Uygulama Şekli } \\
\hline Yapraktan & 31.4 & 38.6 & 40.5 \\
\hline Topraktan & 29.8 & 38.0 & 40.0 \\
\hline$L S D \% 5$ & Ö.D. & Ö.D. & Ö.D. \\
\hline $\mathrm{P}$ & 0.0681 & 0.4746 & 0.6527 \\
\hline \multicolumn{4}{|l|}{ İnteraksiyon } \\
\hline$L S D \% 5$ & Ö.D. & Ö.D. & Ö.D. \\
\hline $\mathrm{P}$ & 0.3817 & 0.8841 & 0.0763 \\
\hline
\end{tabular}

*: Aynı sütun içerisinde farklı harflerle gösterilen ortalamalar arasında istatistiki farklılık bulunmaktadır. $\mathrm{P} \leq 0.05$. Ö.D.: Önemli Değil.

Çizelge 7. Organik ve organomineral gübre uygulamalarının yaprak sıcaklığı $\left({ }^{\circ} \mathrm{C}\right)$ üzerine etkisi.

Table 7. The effect of organic and organomineral fertilizer applications on leaf temperature $\left({ }^{\circ} \mathrm{C}\right)$.

\begin{tabular}{|c|c|c|c|}
\hline Uygulama & Tam Çiçeklenme 14.05.2019 & Ben Düşme 23.06.2019 & Olgunluk 05.07.2019 \\
\hline \multicolumn{4}{|l|}{ Gübre Tipi } \\
\hline Kontrol & $35.2 \mathrm{ab}^{*}$ & $31.7 \mathrm{ab}$ & 34.3 \\
\hline Organik & $35.2 \mathrm{ab}$ & $30.4 \mathrm{~b}$ & 34.2 \\
\hline Organomineral & $36.7 \mathrm{a}$ & $32.0 \mathrm{a}$ & 33.8 \\
\hline Organik+Organomineral & $34.3 \mathrm{~b}$ & $30.8 \mathrm{ab}$ & 33.5 \\
\hline$L S D \% 5$ & 1.6 & 1.6 & Ö.D. \\
\hline $\mathrm{P}$ & 0.0475 & 0.0369 & 0.3804 \\
\hline \multicolumn{4}{|l|}{ Uygulama Şekli } \\
\hline Yapraktan & 35.9 & 31.5 & 34.1 \\
\hline Topraktan & 34.8 & 31.0 & 33.8 \\
\hline$L S D \% 5$ & Ö.D. & Ö.D. & Ö.D. \\
\hline $\mathrm{P}$ & 0.0632 & 0.3260 & 0.3653 \\
\hline \multicolumn{4}{|l|}{ İnteraksiyon } \\
\hline$L S D \% 5$ & Ö.D. & Ö.D. & Ö.D. \\
\hline $\mathrm{P}$ & 0.6592 & 0.2395 & 0.5942 \\
\hline
\end{tabular}

*: Aynı sütun içerisinde farklı harflerle gösterilen ortalamalar arasında istatistiki farklılık bulunmaktadır. P $\leq 0.05$. Ö.D.: Önemli Değil.

Deneme parsellerinden derim sonrasinda alınan toprak örneklerinden, toprağın $\mathrm{K}$ ve $\mathrm{Mg}$ konsantrasyonu ile organik madde içeriği üzerine organik ve organomineral gübre uygulama etkisi önemli; $\mathrm{P}, \mathrm{Ca}, \mathrm{Fe}, \mathrm{Zn}, \mathrm{Mn}$ ve $\mathrm{Cu}$ konsantrasyonu ile $\mathrm{pH}$ ve EC üzerine etkileri ise önemsiz bulunmuştur. En yüksek potasyum (344.5 $\left.\mathrm{mg} \mathrm{kg}^{-1}\right)$ değeri organik+organomineral; magnezyum $\left(266.0 \mathrm{mg} \mathrm{kg}^{-1}\right)$ değeri organik uygulamasından alınmıştır. Organik madde içeriği değerleri, kontrol (\%1.03), organik+organomineral (\%0.92), organik $(\% 0.78)$ ve organomineral $(\% 0.58)$ şeklinde sıralanmıştır. Uygulama şeklinin toprak özellikleri üzerine etkisi önemli çıkmamıştır. (Çizelge 8). Derim dönemindeki toprak değerlerinin Aksu (2008)'ya göre değerlendirilmesinde P, K, $\mathrm{Ca}, \mathrm{Mg}, \mathrm{Zn}$ ve $\mathrm{Cu}$ konsantrasyonlarının tüm uygulamalarda yeterli; Mn'nin organik uygulamasında az, diğer uygulamalarda yeterli; Fe konsantrasyonunun ise fazla olduğu belirlenmiştir.

Farklı gübre uygulamalarının yaprakların azot, demir, çinko ve bakır konsantrasyonu üzerine etkisi önemli bulunmuştur. En yüksek azot değerinin (\%2.27), kontrol uygulamasından; demir değerinin kontrol (134 mg kg-1) ve organik gübre $\left(131 \mathrm{mg} \mathrm{kg}^{-1}\right)$ uygulamalarından; çinko ve bakır değerinin ise (sırasıyla 15.9 $\mathrm{mg} \mathrm{kg}^{-1}, \quad 9.08 \mathrm{mg} \mathrm{kg}^{-1}$ ) organik uygulamasından alındığ görülmektedir. Uygulama şeklinin etkisi incelendiğinde en yüksek bakır değerinin $\left(9.26 \mathrm{mg} \mathrm{kg}^{-1}\right)$ topraktan yapılan gübrelemelerde olduğu belirlenmiştir (Çizelge 9). Jones ve ark. (1991)'na göre azot, fosfor, kalsiyum, magnezyum, demir, mangan ve bakır'ın yeterli; potasyum ve çinko'nun noksan olduğu saptanmıştır. Ojetayo ve ark. (2011) lahanada, mineral gübre ile organik gübre kombinasyonunun, potasyum, kalsiyum ve magnezyum konsantrasyonunu artırabileceğini ve organomineral gübrelerin yalnızca mineral gübre kullanımına göre daha iyi sonuçlar verdiğini belirlemişlerdir.

\section{Sonuçlar}

Sonuç olarak, çalışmada incelenen çoğu özellikler üzerine gübre tipinin önemli, gübre uygulama şeklinin kısmen önemsiz olduğu saptanmıştır. Denemede incelenen verim ve salkım 
Çizelge 8. Organik ve organomineral gübre uygulamalarının toprağın makro ve mikro element, pH, EC, organik madde ve kireç içeriğine etkisi. Table 8. Effects of organic and organomineral fertilizer applications on soil macro and micro elements, pH, EC, organic matter and lime content.

\begin{tabular}{|c|c|c|c|c|c|c|c|c|c|c|c|c|}
\hline \multirow{2}{*}{$\begin{array}{l}\text { Uygulama } \\
\text { Gübre Tipi } \\
\end{array}$} & \multicolumn{4}{|c|}{ Makro elementler $\left(\mathrm{mg} \mathrm{kg}^{-1}\right)$} & \multicolumn{4}{|c|}{ Mikro elementler $\left(\mathrm{mg} \mathrm{kg}^{-1}\right)$} & \multirow{2}{*}{$\mathbf{p H}$} & \multirow{2}{*}{$\begin{array}{c}\mathrm{EC} \\
\left(\mu \mathrm{cm}^{-1}\right)\end{array}$} & \multirow{2}{*}{$\begin{array}{c}\text { Organik } \\
\text { Madde }\end{array}$} & \multirow{2}{*}{ Kireç } \\
\hline & $\mathrm{P}$ & $\mathrm{K}$ & $\mathrm{Ca}$ & $\mathrm{Mg}$ & $\mathrm{Fe}$ & $\mathrm{Zn}$ & $\mathrm{Mn}$ & $\mathrm{Cu}$ & & & & \\
\hline Kontrol & 9.45 & $295.3 b^{*}$ & 2028 & $224.6 \mathrm{ab}$ & 4.72 & 1.77 & 15.11 & 8.14 & 7.5 & 264 & $1.03 \mathrm{a}$ & 45.15 \\
\hline Organik & 9.78 & $331.5 \mathrm{ab}$ & 1888 & $266.0 \mathrm{a}$ & 4.92 & 1.94 & 13.87 & 8.41 & 7.5 & 271 & $0.78 \mathrm{c}$ & 47.68 \\
\hline Organomineral & 8.37 & $302.8 \mathrm{ab}$ & 1988 & $231.9 \mathrm{ab}$ & 4.85 & 1.68 & 14.28 & 7.33 & 7.4 & 278 & $0.58 \mathrm{~d}$ & 49.20 \\
\hline Organik+Organomineral & 10.01 & $344.5 \mathrm{a}$ & 1939 & $200.3 \mathrm{~b}$ & 5.02 & 1.80 & 14.09 & 9.21 & 7.5 & 283 & $0.92 \mathrm{~b}$ & 49.36 \\
\hline$L S D \% 5$ & Ö.D. & 3.34 & Ö.D. & 59.6 & Ö.D. & Ö.D. & Ö.D. & Ö.D. & Ö.D. & Ö.D. & 0.09 & Ö.D. \\
\hline $\mathrm{P}$ & 0.286 & 0.099 & 0.616 & 0.162 & 0.624 & 0.270 & 0.288 & 0.216 & 0.017 & 0.639 & $<0.0001$ & 0.791 \\
\hline \multicolumn{13}{|l|}{ Uygulama Şekli } \\
\hline Yapraktan & 9.61 & 328.7 & 1978 & 217.4 & 4.90 & 1.88 & 14.30 & 8.14 & 7.5 & 266 & 0.79 & 47.75 \\
\hline Topraktan & 9.19 & 308.4 & 1943 & 244.1 & 4.85 & 1.72 & 14.38 & 8.40 & 7.5 & 282 & 0.86 & 47.94 \\
\hline$L S D \% 5$ & Ö.D. & Ö.D. & Ö.D. & Ö.D. & Ö.D. & Ö.D. & Ö.D. & Ö.D. & Ö.D. & Ö.D. & Ö.D. & Ö.D. \\
\hline $\mathrm{P}$ & 0.500 & 0.172 & 0.664 & 0.178 & 0.755 & 0.115 & 0.860 & 0.662 & 0.685 & 0.212 & 0.065 & 0.955 \\
\hline \multicolumn{13}{|l|}{ İnteraksiyon } \\
\hline$L S D \% 5$ & Ö.D. & Ö.D. & Ö.D. & 84.3 & Ö.D. & Ö.D. & Ö.D. & Ö.D. & Ö.D. & Ö.D. & 0.13 & Ö.D. \\
\hline $\mathrm{P}$ & 0.130 & 0.333 & 0.359 & 0.044 & 0.076 & 0.109 & 0.842 & 0.174 & 0.565 & 0.796 & 0.004 & 0.969 \\
\hline
\end{tabular}

Çizelge 9. Organik ve organomineral gübre uygulamaların yaprak besin elementi konsantrasyonuna etkisi.

Table 9. The effect of organic and organomineral fertilizer applications on leaf nutrient concentration.

\begin{tabular}{|c|c|c|c|c|c|c|c|c|c|c|}
\hline \multirow{2}{*}{\multicolumn{2}{|c|}{ Uygulama }} & \multicolumn{5}{|c|}{ Makro elementler (\%) } & \multicolumn{4}{|c|}{ Mikro elementler $\left(\mathrm{mg} \mathrm{kg}^{-1}\right)$} \\
\hline & & $\mathrm{N}$ & $\mathrm{P}$ & $\mathrm{K}$ & $\mathrm{Ca}$ & $\mathrm{Mg}$ & $\mathrm{Fe}$ & $\mathrm{Zn}$ & $\mathrm{Mn}$ & $\mathrm{Cu}$ \\
\hline \multicolumn{11}{|c|}{ Gübre Tipi } \\
\hline \multicolumn{2}{|c|}{ Kontrol } & $2.27 \mathrm{a}^{*}$ & 0.18 & 0.32 & 2.37 & 0.50 & $134 \mathrm{a}$ & $15.6 \mathrm{ab}$ & 117 & $8.47 \mathrm{ab}$ \\
\hline \multicolumn{2}{|l|}{ Organik } & $2.06 \mathrm{ab}$ & 0.17 & 0.38 & 2.56 & 0.56 & $131 \mathrm{a}$ & $15.9 \mathrm{a}$ & 142 & $9.08 \mathrm{a}$ \\
\hline \multicolumn{2}{|c|}{ Organomineral } & $2.24 \mathrm{ab}$ & 0.15 & 0.31 & 2.34 & 0.46 & $120 \mathrm{ab}$ & $14.4 \mathrm{ab}$ & 112 & $8.49 \mathrm{ab}$ \\
\hline \multicolumn{2}{|c|}{ Organik+Organomineral } & $1.93 \mathrm{~b}$ & 0.18 & 0.52 & 2.11 & 0.60 & $104 \mathrm{~b}$ & $12.7 \mathrm{~b}$ & 126 & $7.55 \mathrm{~b}$ \\
\hline \multicolumn{2}{|c|}{ LSD $\% 5$} & 0.33 & Ö.D. & Ö.D. & Ö.D. & Ö.D. & 23.4 & 3.0 & Ö.D. & 1.38 \\
\hline \multicolumn{2}{|l|}{$\mathrm{P}$} & 0.045 & 0.150 & 0.236 & 0.287 & 0.292 & 0.062 & 0.040 & 0.205 & 0.166 \\
\hline \multicolumn{11}{|c|}{ Uygulama Şekli } \\
\hline \multicolumn{2}{|c|}{ Yapraktan } & 2.11 & 0.16 & 0.39 & 2.23 & 0.53 & 115 & 13.6 & 117 & $7.53 \mathrm{~b}$ \\
\hline \multicolumn{2}{|l|}{ Topraktan } & 2.14 & 0.18 & 0.37 & 2.45 & 0.53 & 129 & 15.6 & 131 & $9.26 \mathrm{a}$ \\
\hline \multicolumn{2}{|l|}{ LSD \%5 } & Ö.D. & Ö.D. & Ö.D. & Ö.D. & Ö.D. & Ö.D. & Ö.D. & Ö.D. & 0.97 \\
\hline \multicolumn{2}{|l|}{$\mathrm{P}$} & 0.788 & 0.250 & 0.821 & 0.187 & 0.962 & 0.101 & 0.065 & 0.215 & 0.002 \\
\hline \multicolumn{11}{|c|}{ İnteraksiyon } \\
\hline \multirow{2}{*}{\multicolumn{2}{|c|}{$\begin{array}{l}\text { LSD \%5 } \\
\mathrm{P}\end{array}$}} & Ö.D. & Ö.D. & Ö.D. & Ö.D. & 0.22 & Ö.D. & Ö.D. & Ö.D. & 1.93 \\
\hline & & 0.219 & 0.117 & 0.494 & 0.664 & 0.032 & 0.219 & 0.567 & 0.862 & 0.076 \\
\hline \multirow{3}{*}{$\begin{array}{c}\text { Sinır } \\
\text { Değerleri }\end{array}$} & Noksan & $1.50-1.99$ & $<0.15$ & $1.00-1.29$ & $1.50-1.99$ & $<0.30$ & $<40$ & $18-24$ & $<30$ & $3-4$ \\
\hline & Yeterli & $2.00-2.40$ & $0.15-0.50$ & $1.30-1.40$ & $2.00-2.50$ & $0.30-1.50$ & $40-300$ & $25-100$ & $30-150$ & $5-50$ \\
\hline & Fazla & $>2.40$ & $>0.50$ & $>1.40$ & $>2.50$ & $>1.50$ & $>300$ & $>100$ & $>150$ & $>50$ \\
\hline
\end{tabular}

*: Aynı sütun içerisinde farklı harflerle gösterilen ortalamalar arasında istatistiki farklılık bulunmaktadır. P $\leq 0.05$. Ö.D.: Önemli Değil. ${ }^{\text {}: ~ S ı n ı r ~ D e g ̆ e r l e r i ~(J o n e s ~ v e ~ a r k . ~}$ 1991)

ağırlığı ile kısmen tane özellikleri bakımından organomineral gübrenin yalnız ve birlikte uygulamalarından olumlu sonuçlar alınmıştır. Gübrelerin özellikle yaprak besin elementi üzerine etkilerinde saptanan bir miktar iyileşme, etkinin sonraki yıllarda da süreceğinin işaretleri olarak görülmüştür. Yapraktan uygulama ile toprak uygulaması arasında çoğu kez önemli farklılıkların çıkmaması da bu gübrelerin asmanın her fenolojik döneminde gerektiğinde uygulanabilme avantajlarına sahip olduklarını göstermiştir. Asma gibi çok yıllık bitkilerde gübrelerin biriken etkisinin görülebilmesi için çalışmanın izleyen yıllarda da sürdürülmesinin yararlı olacağı düşünülmektedir.

\section{Teşekkür}

$\mathrm{Bu}$ çalışma, Çukurova Üniversitesi Bilimsel Araştırma Projeleri Koordinasyon Birimi tarafindan (Proje No: FYL-201911584) desteklenmiştir.

\section{Acknowledgment}

This study was supported by the Scientific Research Projects Coordination Unit of Cukurova University (Project No: FYL-2019-11584). 


\section{Kaynaklar}

Ahmed MA, Kassem HA, Al-Obeed RS (2018) Effect of organomineral fertilizers on Sakki Date Palm "Phoenix dactylifera L." fruits yield, quality and nutritional value. Bothalia Journal 43(11): 103-116.

Aksu A (2008) Ege bölgesinde yaygın bağcılık yapılan alanlarda tuzluluk, bor toksitesi problemlerinin ve beslenme durumunun belirlenmesi. Yüksek Lisans Tezi, Ankara Üniversitesi Fen Bilimleri Enstitüsü, Ankara.

Akural M (2009) Geleneksel tarım ve çevre kirliliği ilişkisi. http://www.eto.org.tr/ 2009/05/geleneksel-tarim-ve-cevre-kirliligiiliskisi/. Erişim 3 Ocak 2019.

Aslan N (2018) Organomineral gübre kullanımının Antepfistı̆̆ 1 verimi ve toprağın fiksasyon kapasitesi üzerine etkisi (Ed: Kınacı E). Organomineral Gübre Çalıştayı Bildiriler, 1. Baskı, Sena Ofset Ambalaj Matbaacıllk, İstanbul, s. 192-200.

Ateş E, Tekeli AS (2017) Farklı taban gübresi uygulamalarının yem bezelyesi (Pisum arvense L.)'nin ot verimi ve kalitesine etkisi. Kahramanmaraş Sütçü İmam Üniversitesi Doğa Bilimleri Dergisi 20(Özel Sayı): 13-16.

Bremner JM (2065) Total Nitrogen. In: C. A. Black (ed.) Methods of Soil Analysis. Part 2: Chemical and Microbial Properties. Number 9 in series Agronomy. American Society of Agronomy, Inc. Publisher, Madison, USA. pp. 1049-1178.

Çalışkan Ö, Ayan AK (2011) Isırgan'da (Urtica dioica L.) farklı dozlarda NPK'lı organo mineral gübrenin verim ve bazı verim komponentlerine etkisi. Anadolu Tarım Bilimleri Dergisi 26(3): 217-220.

Çelik S (2011) Bağcılık (Ampeloloji). Trakya Üniversitesi Tekirdağ Ziraat Fakültesi Bahçe Bitkileri Bölümü. Avcı Ofset, İstanbul.

Dannehl D, Becker C, Suhl J, Josuttis M, Schmidt U (2016) Reuse of organomineral substrate wastefrom hydroponic systems as fertilizer in open-field production increases yields, flavonoid glycosides and caffeic acid derivatives of red oak leaf lettuce (Lactuca sativa L.) much morethan synthetic fertilizer. Journal of Agricultural and Food Chemistry 64: 7068-7075.

Fernandes ALT, Rodrigues GP, Testezlaf R (2003) Mineral and organomineral fertirrigation in relationto quality of greenhouse cultivated melon. Scientia Agricola 60(1): 149-154.

Follet RH (1969) Zn, Fe, Mn and Cu in Colorado Soils. Ph. D. Dissertation. Colo. State University.

Hızalan E, Ünal H (1966) Topraklarda Önemli Kimyasal Analizler. Ankara Üniversitesi Ziraat Fakültesi Yayınları, Ankara.

Jackson ML (1958) Soil Chemical Analysis. Prentice-Hall, Inc. Englewood Cliffs, New Jersey, USA, pp. 1-498.

Jones Jr JB, Wolf B, Mills HA (1991) Plant Analysis Handbook: A Practical Sampling, Preparation, Analysis, and Interpretation Guide. Micro-Macro Publishing, Athens.

Kacar B (1972) Bitki ve Toprağın Kimyasal Analizleri. II. Bitki Analizleri. Ankara Üniversitesi Ziraat Fakültesi Yayınları 453, Uygulama Kılavuzu 155, Ankara Üniversitesi Basımevi, Ankara.

Katkat V (2018) Organomineral Gübre Çalıştayı Bildiriler (Ed: Kınacı E). Sena Ofset Ambalaj Matbaacilık, İstanbul.

Kolbe AR, Aira M, Gomez-Brandon M, Perez-Losada M, Dominguez J (2019) Bacterial succession and functional diversity during vermicomposting of the white grape marc Vitis vinifera $\mathrm{v}$. Albarino. Scientific Reports 9: 7472.

Kominko H, Gorazda K, Wzorek Z (2016) The possibility of organomineral fertilizer production from Sewage Sludge. Waste Biomass Valor 8: 1781-1791.

Küçükbasmacı AÖ (2019) Farklı asma anaçları üzerine aşı1ı Prima sofralık üzüm çeşidinin kısıntılı sulama koşullarına tepkileri. Yüksek Lisans Tezi, Selçuk Üniversitesi Fen Bilimleri Enstitüsü, Konya.
Lindsay WL, Norwell WA (1969) Development of a DTPA Micronutrient Soil Test. Soil Science Society of America Proceedings 35: 600-602.

Lindsay WL, Norwell WA (1978) Development of a DTPA Soil Test for Zinc, Iron, Manganese and Copper. Soil Science Society of America Journal 42: 421-428.

Morlat R (2008) Long-term additions of organic amendments in a Loire Valley vineyard on a calcareous sandy soil. II. Effects on root system, growth, grape yield, and foliar nutrient status of a Cabernet franc vine. American Journal of Enology and Viticulture 59: 364-374.

Ojetayo AE, Olayini JO, Akanbi WB, Olabiyi TI (2011) Effect of fertilizer types on nutritional quality of two cabbage varieties before and after storage. Journal of Applied Biosciences 48: 33223330 .

Ojo JA, Olowoake AA, Obembe A (2014) Efficacy of organomineral fertilizer and un-amended compost on the growth and yield of watermelon (Citrullus lanatus Thumb) in llorin Southern Guinea Savanna zone of Nigeria. International Journal of Recycling Organic Waste in Agriculture 3: 121-125.

Olaniyi JO, Akanbi WB (2007) Effect of organo mineral and inorganic fertilizers on the yield quality of fluted pumpkin (Telfaria Occidentalis Hook. F.). African Crop Science Conference Proceedings 8: 347-350.

Olaniyi JO, Akanbi WB, Olaniran OA, Ilupeju OT (2010) The effect of organo-mineral and inorganic fertilizers on the growth, fruityield, quality and chemical compositions of Okra. Journal of Animal and Plant Sciences 9(1): 1135-1140.

Olaniyi JO, Ogunbiyi EM, Alagbe DD (2009) Effects of organo-mineral fertilizers on growth, yield and mineral nutrients uptake in Cucumber. Journal of Animal and Plant Sciences 5(1): 437-442.

Olaniyi JO, Ojetayo AE (2011) Effect of fertilizer types on the growth and yield of two cabbage varieties. Journal of Animal and Plant Sciences 12(2): 1573-1582.

Olsen SR, Cole CV, Watanabe FS, Dean NC (1954) Estimation of available phosphous in soil by extraction with sodium bicorbonate. Circular, 939: 19. Washington, DC: US Department of Agriculture.

Özdemir G (2018) Organik ve organomineral gübre uygulamalarının Öküzgözü ve Boğazkere üzüm çeşitlerinin sürgün gelişimi üzerine etkilerinin belirlenmesi. International Congress on Agriculture and Animal Sciences, Alanya, Türkiye.

Özdemir G, Kitir N, Turan M, Özlü E (2018) Impacts of organic and organo-mineral fertilizers on total phenolic, flavonoid, anthocyanin and antiradical activity of Okuzgozu (Vitisvinifera L.) grapes. Acta Scientiarum Polonorum Hortorum Cultus 17(3): 91-100.

Pekcan T, Turan HS, Çolakoğlu H (2009) Effects of organomineral, mineral and farmyard manures on the yield and quality of Olive Trees (Olea Europaea L.). The Proceedings of the International Plant Nutrition Colloquium XVI. Department of Plant Sciences, UC Davis, California, USA.

Pratt M (1965) Potassium and sodium. In: Black CA (ed) Methods of soil analysis. American Society of Agronomy, Inc., Madison, Wisconsin, pp. 1022-1034.

Richards LA (1954) Diagnosis and improvement of saline alkali soils. Agriculture handbook 60. US Department of Agriculture, Washington DC. pp. 160.

Rozpara E, Pasko M, Bielicki P, Paszt LS, Glowacka A (2015) The influence of some bio-products on the growth, yielding and fruit quality of 'Debreceni Bötermö' sour cherry trees cultivated in an organic orchard. Journal of Research and Applications in Agricultural Engineering 60(4): 76-79.

Sarı G (2019) Çinko uygulamalarının kısıntılı sulama şartlarında 'Alphonse Lavallèe' ve 'Italia' sofralık üzüm çeşitlerinin gelişimi ve fizyolojisine etkileri. Yüksek Lisans Tezi, Selçuk Üniversitesi Fen Bilimleri Enstitüsü, Konya. 
Tangolar S, Özdemir G, Gürsöz S, Cakır A, Gök Tangolar S (2007) Bazı organik gübre uygulamalarını asmanın (Vitis vinifera $\mathrm{L}$. Çiloreş) fenolojik gelişmesi ile salkım, tane ve şıra özellikleri üzerine etkisi. Akdeniz Üniversitesi Ziraat Fakültesi Dergisi 20(2): 319-325.

Tangolar S, Tangolar S, Alkan Torun A, Ada M, Aydın O (2019) Bağ toprağına uygulanan organik materyallerin verim, kalite ve besin elementleri alımına etkisi. Mediterranean Agricultural Sciences, 32: 135-140.

Tarakçıoğlu C, Aşkın T (2006) Organomineral gübrenin Kivi bitkisinin verim ile yapraklarının besin maddesi içerikleri üzerine etkisi. II. Ulusal Üzümsü Meyveler Sempozyumu, Tokat.
TÜIK (2018) Bitkisel Üretim İstatistikleri. http://www.tuik.gov.tr/PreTablo.do?altid =1001. Erişim 5 Mayıs 2020.

Tüzüner A (1990) Toprak ve Su Analiz Laboratuarı El Kitabı. Tarım Orman ve Köy İşleri Bakanlığı Köy Hizmetleri Genel Müdürlüğü.

Wolf B (1971) The determination of boron in soil extracts, plant materials, composts, manures, water and nutrient solutions. Soil Science and Plant Analysis 2(5): 363-374. 